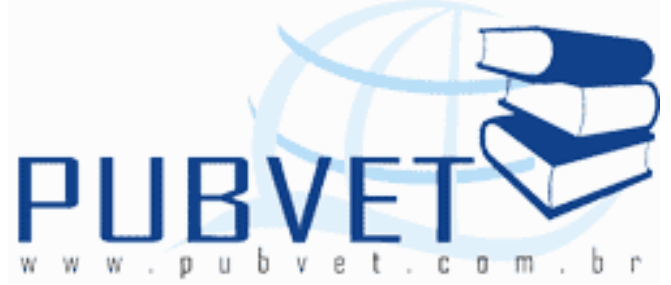

PUBVET, Publicações em Medicina Veterinária e Zootecnia.

\title{
Sobrevivência de Escherichia coli 0157:H7 em iogurtes contaminados pós-fermentação
}

Paula Aparecida Martins Borges Bastos ${ }^{1 *}$, Robson Maia Franco ${ }^{2}$, Sérgio Borges Mano $^{2}$, Marco Antonio Sloboda Cortez ${ }^{2}$

1 Médica Veterinária, Laboratório de Microbiologia de Alimentos, campus Bom Jesus do Itabapoana, Instituto Federal de Educação, Ciência e Tecnologia Fluminense, Av. Dario Vieira Borges, 235, CEP 28.360-000, Bom Jesus do Itabapoana, RJ, Brasil. E-mail: pabastos@iff.edu.br

${ }^{2}$ Médico Veterinário, Departamento de Tecnologia de Alimentos, Faculdade de Medicina Veterinária, Universidade Federal Fluminense, R. Vital Brazil Filho, 64, Niterói, RJ, Brasil.

\section{Resumo}

A sobrevivência de Escherichia coli O157:H7 em iogurte integral e desnatado estocado em refrigeração a $4,0^{\circ} \mathrm{C} \pm 2,0^{\circ} \mathrm{C}$ foi pesquisada durante 30 dias. Uma cultura comercial liofilizada mista (2:1) de Streptococcus thermophilus and Lactobacillus delbrueckii subsp. bulgaricus foi utilizada para a produção do iogurte. Os iogurtes foram produzidos com dois tipos de matéria-prima: leite integral ( $3,4 \% \mathrm{v} / \mathrm{v}$ teor de gordura) e desnatado ( $<0,5 \% \mathrm{v} / \mathrm{v}$ teor de gordura). Para cada tratamento foi obtido o grupo controle e o iogurte inoculado com Escherichia coli 0157:H7 (CDC EDL-933) com uma population de 4,36 log UFC/mL. Durante os 30 dias de estocagem a enumeração de $S$. thermophilus e 
L. delbrueckii subsp. bulgaricus foi de 8-9 log UFC/mL em todos os tratamentos. E. coli 0157:H7 não foi detectável a partir do quinto dia em ambos os tipos de iogurtes. Esses resultados revelam que o crescimento de $E$. coli 0157:H7 foi inibido durante o período de estocagem e que o patógeno permaneceu viável por poucos dias na fase lag. Não foi detectado diferença aparente entre $\mathrm{pH}$ e acidez titulável entre os tipos de iogurte. $\mathrm{O} \mathrm{pH}$ do iogurte imediatamente após a fermentação foi de 4,7-4,8 e caiu até 4,3-4,4 ns últimas semanas de estocagem. O percentual de ácido lático foi inicialmente de 0,66 e 0,68 para iogurte integral e desnatado, respectivamente. Os resultados indicam que não houve diferença entre iogurtes com diferente teores de gordura (integral e desnatado) sobre as populações de bactérias ácido láticas e E coli $\mathrm{O} 157: \mathrm{H7}$ e embora as contagens do patógeno tenham decrescido continuamente, sua presença foi detectada até o quarto dia de estocagem. Palavras-chave: Escherichia coli O157:H7; sobrevivência microbiana; iogurte; leite fermentado; bactéria ácido lática.

\title{
Survival of Escherichia coli 0157:H7 in yoghurts contaminated post- fermentation
}

\begin{abstract}
The survival of Escherichia coli $0157: \mathrm{H7}$ in whole and skimmed yoghurt was investigated during 30 days of storage under refrigeration at $4.0^{\circ} \mathrm{C} \pm 2.0^{\circ} \mathrm{C}$. A commercial lyophilized mixed (2:1) culture of Streptococcus thermophilus and Lactobacillus delbrueckii subsp. bulgaricus was used for the yoghurt production. Yoghurts were manufactured from two kinds of raw milk: whole milk ( $3.4 \% \mathrm{v} / \mathrm{v}$ fat content) and skimmed milk ( $<0.5 \% \mathrm{v} / \mathrm{v}$ fat content). From each treatment were obtained the control and the yoghurt inoculated with Escherichia coli O157:H7 (CDC EDL-933) at a population of log $4.36 \mathrm{CFU} \cdot \mathrm{mL}^{-1}$. During the 30 days of storage the enumeration of $S$. thermophilus and $L$. delbrueckii subsp. bulgaricus were log 8-9 CFU. $\mathrm{mL}^{-1}$ to all treatments. E. coli O157:H7 was undetectable at day 5 in both whole and skimmed yoghurt.
\end{abstract}


These results reveal that growth of E. coli $0157: \mathrm{H} 7$ was inhibited during storage period and the pathogen was kept alive for few days in lag phase. The $\mathrm{pH}$ and titratable acidity did not reveal apparent difference among yoghurt types. The $\mathrm{pH}$ of yoghurt immediately after fermentation was 4.7-4.8 and dropped until 4.3-4.4 in the last weeks of storage. The acid lactic percentage was initially 0.66 and 0.68 for whole and skimmed yoghurt, respectively. Results indicated that effects of the yoghurt with low or whole fat were not different on starter lactic acid bacteria and E coli 0157:H7 populations and although the pathogen counts decreased continually, they were detectable until four days during storage.

Keywords: Escherichia coli O157:H7; microbial survival; yoghurt; fermented milk; lactic acid bacteria.

\section{Introdução}

Os alimentos fermentados foram considerados durante um longo período como alimentos seguros devido a seu baixo pH e capacidade de inibição de micro-organismos. Após vários surtos, entretanto, a presença de patógenos causadores de doenças transmissíveis por alimento em tais produtos tem se tornado uma grande preocupação nas décadas recentes $(1,35)$.

Escherichia coli 0157:H7 é um importante patógeno causador de doenças transmissíveis por alimento. Pode ser definido como um membro do grupo enterohemorrágico (EHEC) e pode causar algumas doenças graves, como a colite hemorrágica, trombocitopenia trombótica púrpura e síndrome urêmica hemolítica. Crianças e idosos fazem parte do grupo mais susceptível a sua patogenicidade $(8,24,34)$. A grande resistência ao ácido de $E$. coli 0157:H7 é considerada uma das principais causas de surtos em alimentos fermentados contaminados. Sua capacidade de infectar com doses mínimas de até $10 \mathrm{UFC} / \mathrm{mL}$ é também um importante mecanismo de doenças infecciosas e surtos de alguns alimentos fermentados com baixos níveis do patógeno podem estar associados com um possível efeito protetor da gordura $(1,6,15,20)$. 
Tem ocorrido um aumento no número de estudos para determinar a sobrevivência de $E$. coli $0157: \mathrm{H7}$ em vários leites fermentados disponíveis no mercado em todo o mundo $(5,10,11,26,30)$. Isso é essencial para a saúde pública porque com esses conhecimentos será possível realizar um valor preditivo mais acurado sobre a segurança dos leites fermentados.

Iogurte é um alimento fermentado altamente consumido em todo o mundo. O procedimento de produção é diferente de acordo com os consumidores regionais, com algumas variações nos constituintes e no tipo de Bactéria Ácido Lática (BAL) ou nas concentrações usadas nas culturas iniciadoras (3). Iogurte foi considerado um alimento seguro por muitos anos. Esse conceito foi revisto após um surto de Escherichia coli 0157:H7 relacionado com o consumo de iogurte produzido localmente no Reino Unido, envolvendo principalmente crianças (25).

A sobrevivência de $E$. coli em iogurte é dependente de muitas variantes tais como o tipo de cepa, a dose do inoculo, o estágio de contaminação (pré ou pós-fermentação) e o tipo de bactéria ácido lática utilizado $(5,11,18,19,21$, $22,23,26,27,31,32$ ).

A despeito do conhecido efeito protetor da gordura sobre patógenos como E. coli (20), não há referência específica quanto ao aumento do risco de doenças transmissíveis por alimento pelo consumo de iogurte contaminado desnatado comparado com iogurte integral.

O objetivo desta pesquisa foi determinar a sobrevivência de $E$. coli O157:H7 em iogurte desnatado e integral durante 30 dias de estocagem sob refrigeração a $4,0^{\circ} \mathrm{C} \pm 2$.

\section{Material e Métodos}

Ácido lático iniciadoras - uma cultura comercial liofilizada mista (2:1) de Streptococcus thermophilus e Lactobacillus delbrueckii subsp. bulgaricus denominada YC-X11 - Yo-Flex® (Chr. Hansen Ltda) foi usada para produção do iogurte. A cultura mista foi diluída em um litro de leite em pó desnatado 
reconstituído esterilizado, agitada para homogeneização e imediatamente usado em percentagem de inoculação de 50 U DVS para 500 litros de leite.

Preparo do inóculo de Escherichia coli - Escherichia coli 0157:H7 (CDC EDL-933) foi obtida da coleção de cultura do Instituto Nacional de Controle de Qualidade em Saúde, Fundação Oswaldo Cruz, Rio de Janeiro, Brasil.

O organismo foi inoculado em Ágar Nutriente (Merck $®$, Darmstadt, Germany) e incubado a $37^{\circ} \mathrm{C}$ durante 24 horas. A cultura foi transferida para solução salina esterilizada $(0,85 \% \mathrm{p} / \mathrm{v}, \mathrm{NaCl}$ (Vetec $\Re$, Rio de Janeiro, Brasil)) com uma alça de platina até que a concentração alcançasse escala 0,5 de MacFarland. Uma suspensão de um mililitro de $E$. coli foi inoculada imediatamente pós-fermentação em $750 \mathrm{~mL}$ de iogurte. O nível de inoculação obtido foi de $\log 4,36 \mathrm{UFC} / \mathrm{mL}$.

Produção de iogurte - Leite cru (4,5 litros distribuídos em erlenmeyer com $750 \mathrm{~mL}$ ) foi aquecido a $83^{\circ} \mathrm{C}$ durante 30 minutos em banho-maria, resfriado imediatamente em banho com gelo a $45^{\circ} \mathrm{C}$ e inoculado com a cultura do iogurte. Após homogeneização, as amostras foram incubadas em banhomaria a $45^{\circ} \mathrm{C}$ até que sua acidez alcançasse $0,65 \%$ de ácido lático ou pH 4,8 .

Tipos de iogurte - Os diferentes tipos de iogurte foram manufaturados com dois tipos de leite cru: leite integral $(3,4 \% \mathrm{v} / \mathrm{v}$ de gordura) e leite desnatado ( $<0,5 \% \mathrm{v} / \mathrm{v}$ gordura). Cada tipo foi dividido em partes iguais após a fermentação. A metade foi inoculada com Escherichia coli O157:H7. O iogurte remanescente foi utilizado como controle negativo. Amostras (50 mL) foram transferidas para potes de iogurte de prolipropileno estéreis, identificadas e estocadas refrigeradas a $4,0^{\circ} \mathrm{C} \pm 2,0$ durante 30 dias.

Análises bacteriológicas - A qualidade bacteriológica do leite cru foi determinada pela contagem total em placas de aeróbios mesófilos, com diluições seriadas do leite em solução salina peptonada estéril $(0,1 \% \mathrm{p} / \mathrm{v}$ de peptona (Vetec $\AA$, Rio de Janeiro, Brasil), contendo $0,85 \% \mathrm{p} / \mathrm{v}$ de $\mathrm{NaCl}$ ) e técnica de plaqueamento em profundidade com o meio Ágar Padrão para Contagem (Merck ${ }^{\circledR}$, Darmstadt, Germany). 
Imediatamente após a pasteurização, uma amostra foi coletada para assegurar sua qualidade através de contagem em placas de aeróbios mesófilos e verificação da ausência de coliformes totais e termotolerantes através do método padrão de Número Mais Provável (NMP) (2).

A enumeração de bactérias ácido láticas foi realizada através de diluições seriadas do iogurte em solução de citrato de sódio $2 \%$ (Vetec $($, Rio de Janeiro, Brasil) (29) e técnica de plaqueamento em profundidade nos seguintes meios: Agar M17 (Himedia ${ }^{\circledR}$, Mumbai, Índia) para S. thermophilus e Agar MRS (Vetec $\AA$, Rio de Janeiro, Brasil) para L. delbrueckii subs. bulgaricus. O primeiro foi incubado aerobicamente a $42^{\circ} \mathrm{C}(33$, modificado) durante 48 horas e o segundo em jarra de anaerobiose com atmosfera de $\mathrm{CO}_{2}$ a $37^{\circ} \mathrm{C}$ durante 48 horas. As análises foram realizadas nos tempos $0,2,4,6,8,10,20$ e 30 dias após a produção.

E. coli $\mathrm{O} 157: \mathrm{H} 7$ foi enumerada através de diluição seriada do iogurte em solução salina peptonada e plaqueamento em profundidade em meio VRBA ("Violet Red Bile Agar", Merck $\AA$, Darmstadt, Germany). A contagem das placas foi realizada após incubação aeróbica a $37^{\circ} \mathrm{C}$ durante 24 horas. Populações viáveis de E. coli 0157:H7 foram determinadas diariamente a partir do dia zero até a ausência de detecção.

Foram realizados esfregaços das colônias das placas e coloração pelo método de Gram para confirmação da morfologia bacteriana específica por microscopia de imersão. Todas as análises foram realizadas em duplicata e os resultados foram a média de cada contagem.

Análise de $\mathrm{pH}$ e acidez titulável - $\mathrm{O} \mathrm{pH}$ e a acidez titulável do leite e iogurte foram monitorados a temperatura ambiente durante todos os dias de análise microbiológica. $\mathrm{O}$ pH foi medido com um peagômetro Quimis (Modelo Q-400A, Brasil) em $10 \mathrm{~mL}$ de alíquotas retiradas dos frascos. O eletrodo do $\mathrm{pH}$ foi calibrado com solução tampão (Merck ${ }^{\circledR}$ ) de pH 4,0 e 7,0. Para medir a acidez titulável, $10 \mathrm{~mL}$ das amostras foi titulado com $0,111 \mathrm{NaOH}$ após a adição de $0,5 \mathrm{~mL}$ de fenolftaleína até que a cor apresentasse tom levemente 
rósea persistente. $\mathrm{O} N \mathrm{NaOH}$ em $\mathrm{mL}$ foi registrado e os resultados foram expressos em termos de porcentagem de ácido lático.

Análise estatística - o experimento foi procedido em triplicata. Os dados bacteriológicos foram convertidos para log UFC/mL antes da análise estatística. Diferenças nas contagens bacterianas, acidez e pH foram testadas através da análise de regressão.

\section{Resultados e Discussão}

A qualidade bacteriológica do leite usado na manufatura foi inicialmente determinada. A contagem total em placas do leite cru foi $4,64 \log U F C / m L$. O leite pasteurizado apresentou redução dos níveis de contagem total em placas para $1,47 \log \mathrm{UFC} / \mathrm{mL}$. Os coliformes totais e termotolerantes apresentaram níveis não detectáveis $(<0,3 \mathrm{NMP} / \mathrm{mL}) . \mathrm{O} \mathrm{pH}$ do leite cru integral e desnatado foi $6,88 \pm 0,05$ e 6,88 $\pm 0,06$, respectivamente, e o ácido lático foi de 0,15\% $\pm 0,01$ em todos os tipos de leite. Analisando-se esses resultados, concluiu-se que o leite se encontrava dentro dos padrões de qualidade vigentes.

Não houve diferença significante entre as contagens de bactérias ácido láticas nos iogurte integral e desnatado com ou sem contaminação por $E$. coli O157:H7. Durante os 30 dias de estocagem as contagens permaneceram entre $\log$ 8-9 UFC/mL em ambos S. thermophilus (Fig. 1) e L. delbrueckii subsp. bulgaricus (Fig. 2). Embora iogurte seja consumido em grande parte do mundo, preferências regionais necessitam ser melhor estudadas. Considerando que a cultura comercial iniciadora utilizada nesse experimento foi a mesma usada em muitas indústrias locais brasileiras, os achados corroboram os encontrados por Birollo et al. (3), que encontraram uma preferência por $S$. thermophilus dominante como iniciadoras industriais na Argentina. Esse fato indica uma possível preferência característica no Mercado Comum Sulamericano (MERCOSUL) em usar baixas proporções de $L$. delbrueckii subsp. bulgaricus em cultura iniciadora de iogurte. O lactobacilo é o principal responsável pela produção de aroma no iogurte (28), porém também é responsável pelo contínuo aumento da concentração de ácido lático durante a 
estocagem refrigerada (9). Assim, a opção dos produtores locais pode ser reduzir o problema da pós-acidificação em detrimento do aumento do aroma.

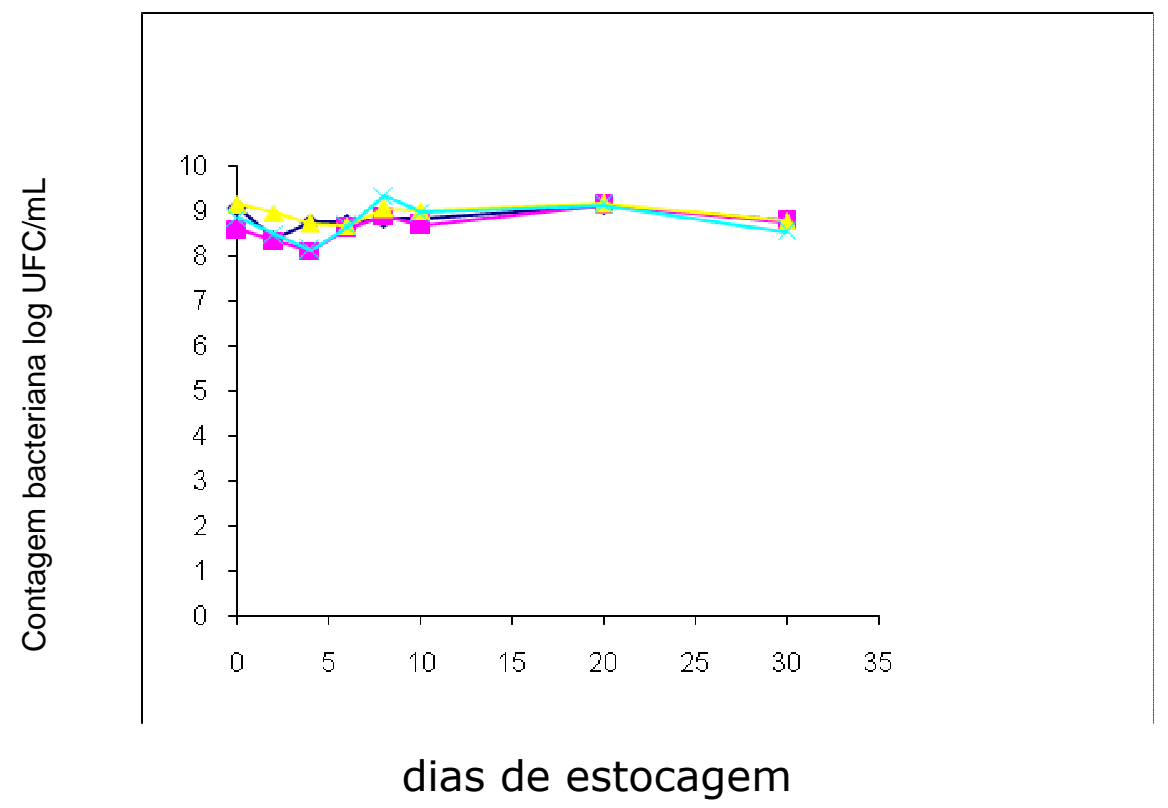

Fig. 1. Representação gráfica dos resultados das contagens de Streptococcus thermophilus em iogurtes estocados a $4^{\circ} \mathrm{C}$ : integral contaminado com E. coli $0157: \mathrm{H} 7(\diamond)$; desnatado contaminado com E. coli $0157: \mathrm{H} 7(\Delta)$; integral não contaminado $(\square)$; desnatado não contaminado $(\times)$.

$\mathrm{O}$ pH e a acidez titulável não apresentaram diferença entre os tratamentos. $\mathrm{O}$ pH do iogurte imediatamente após a fermentação foi de 4,8 e caiu até 4,3-4,4 nas últimas semanas de estocagem. A porcentagem de ácido lático foi inicialmente de 0,66 e 0,68 para iogurte integral e desnatado, respectivamente.

E. coli 0157:H7 sobreviveu em iogurte integral e desnatado até quatro dias de estocagem não sendo detectável no quinto dia (Fig. 3). A população inicial foi de 4,36 log UFC/mL e a contagem decresceu cerca de 1 log por dia a partir do segundo dia. Com base nos resultados encontrados pode-se afirmar que o crescimento de E. coli $\mathrm{O} 157: \mathrm{H7}$ foi inibido durante o período de estocagem e o patógeno foi mantido viável por poucos dias na fase lag, denotando pouca capacidade de crescimento nessas condições. 


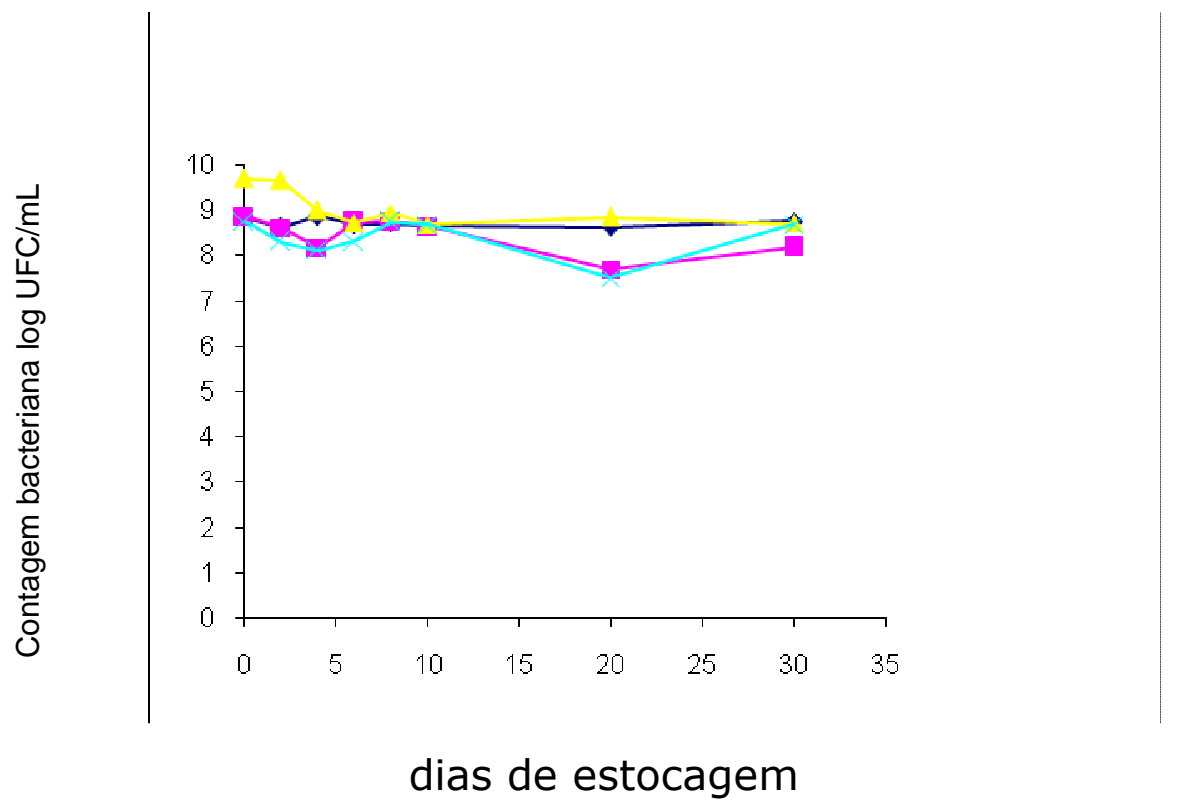

Fig. 2. Representação gráfica das contagens de Lactobacillus bulgaricus em iogurtes estocados a $4^{\circ} \mathrm{C}$ : integral contaminado com E. coli O157: $\mathrm{H7}(\vartheta)$; desnatado contaminado com E. coli O157:H7 ( $\square$ ); integral não contaminado $(\Delta)$; desnatado não contaminado $(\times)$.

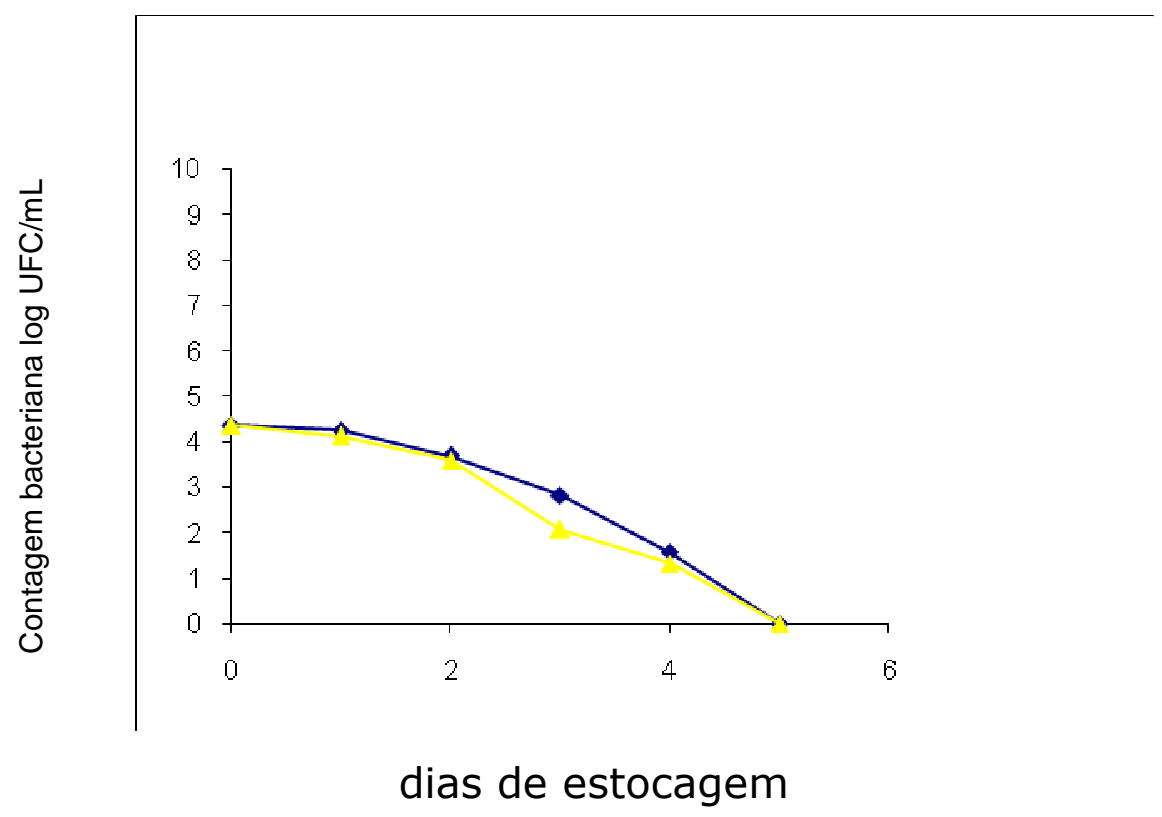

Fig. 3. Representação gráfica das contagens de E. coli O157:H7 em iogurtes integral $(\diamond)$ e desnatado $(\Delta)$ estocados a $4^{\circ} \mathrm{C}$. 
A mesma cepa de E. coli O157:H7 usada no presente estudo (CDC EDL933) foi testada em algumas pesquisas envolvendo comparação de alimentos com diferentes teores de gordura. O conteúdo de gordura não influenciou a contagem populacional de E. coli 0157:H7 (ATCC 43895 e outros) em linguiça tipo "Beef Summer Sausage" com aproximadamente 8 e 17\% de conteúdo de gordura (16). Govaris et al. (17) relataram diferença na sobrevivência de $E$. coli 0157:H7 (uma mistura de EDL-932 e EDL-933) log 5,6 UFC \mL em iogurte de soro de leite, iogurte de leite de vaca e iogurte de leite de ovelha em contaminação pós-fermentação. O patógeno decresceu a um nível indetectável após 17, 14 e 12 dias em iogurte de leite de ovelha, iogurte de leite de vaca e iogurte de soro de leite, respectivamente. Todos os produtos tiveram contagens de $E$. coli $0157: \mathrm{H} 7$ significativamente diferentes $(\mathrm{P}<0,05)$ após dois dias de estocagem a $4^{\circ} \mathrm{C}$. Os autores sugerem que essas taxas de sobrevivência diferentes podem ser devido a diferença na composição do leite, pois nenhum efeito das BAL ou mudança de $\mathrm{pH}$ foi detectado. Na verdade, algumas dessas diferenças poderiam estar na gordura, com leite de vaca, leite desnatado de vaca e leite de ovelha apresentando 3,8; 0,3 e 7,2 de porcentagem de gordura, respectivamente. Entretanto, o teor de gordura deste estudo foi similar àquele do leite de vaca e leite de vaca desnatado, porém não os resultados, que não apresentaram diferença significativa na sobrevivência E. coli O157: $\mathrm{H} 7$ tanto em iogurte integral quanto desnatado. No experimento de Geornaras et al. (14) não houve diferença aparente no efeito antimicrobiano de $\varepsilon$-Poli-lisina contra E. coli O157:H7 (ATCC 43985 entre uma mistura de cepas) em extratos de leite integral e livre de gordura, concluindo esses autores que o teor de gordura não influenciou a atividade desse antimicrobiano. Uma possibilidade para esses achados pode ser que o teor de gordura do iogurte integral não seja suficiente para proteger a bactéria patogênica do ambiente lesivo, uma vez que os achados de influência da gordura sobre a redução das populações de $E$. coli 0157:H7 foram determinados em alimentos com altos teores de gordura como linguiça 
calabresa e "jerked beef" com 30 e $20 \%$ de gordura, respectivamente (12, 13).

A grande variedade de possibilidades nos estágios de contaminação, nível do inoculo e adaptação ao ácido de células de E. coli O157:H7 no iogurte são algumas das questões abordadas por pesquisadores na literatura científica. EHEC 0157:H7

sobreviveu melhor em iogurte batido quando contaminada no estágio de pósfermentação em oposição à pré-fermentação (22). Maiores chances de sobrevivência de células ácido adaptadas de E. coli 0157:H7 (10 $\left.{ }^{7} \mathrm{UFC} / \mathrm{mL}\right)$ foram observadas quando inoculadas na pós-fermentação em contraste com as que não o foram. No primeiro caso a bactéria foi detectável até 22 dias de estocagem e no segundo 18 dias (31). Hsin-Yi e Chou (19) pesquisaram a sobrevivência de E. coli 0157:H7 (ATCC 43985 e ATCC 43889) ácido adaptada e não ácido adaptada em iogurte comercial com baixos teores de gordura inoculado com 6,0 log UFC/mL. O pH inicial foi 3,9 e ambas as cepas declinaram durante a estocagem a $7,0^{\circ} \mathrm{C}$. A cepa ATCC 43889 não foi detectável com quatro e cinco dias para células ácido adaptadas e não ácido adaptadas, respectivamente. A cepa 43895 foi mais resistente, sendo detectável até o sexto dia de estocagem em ambos os casos. Em outra pesquisa com E. coli O157:H7 (E-D10) foi detectada a capacidade do patógeno sobreviver durante sete dias quando iogurte pré-fermentação ( $2 \%$ de cultura iniciadora) foi contaminado com inóculo de $10^{3}$ e $10^{7} \mathrm{UFC} / \mathrm{mL}$, sendo o primeiro inóculo reduzido de log 3,04 (pós-fermentação) para 2,72 (23). Em um experimento com inóculos de E. coli O157:H7 (EDL 931) a uma concentração de $10^{2}, 10^{4}$ e $10^{6} \mathrm{UFC} / \mathrm{mL}$ em iogurte pré-fermentado, as culturas iniciadoras foram $2 \%(\mathrm{v} / \mathrm{v})$ e as contagens de BAL estiveram em torno de $10^{9} \mathrm{UFC} / \mathrm{mL}$ durante todo o período estudado. No tempo de fermentação (em torno de três horas) o patógeno aumentou $1 \log$ e o pH alcançou 4,6. 0 tempo de eliminação de $E$. coli $\mathrm{O} 157: \mathrm{H} 7$ foi de $48 \mathrm{~h}$ para $10^{2}$ e $10^{4} \mathrm{UFC} / \mathrm{mL}$ e de $72 \mathrm{~h}$ para $10^{6} \mathrm{UFC} / \mathrm{mL}(21)$. 
Embora existam relatos em estudos sobre BAL que apontam para a existência de uma série de fatores antimicrobianos como as bacteriocinas, para Adams e Mitchell (1), a produção de altos níveis de ácido orgânico e o conseqüente decréscimo do $\mathrm{pH}$ são a principal contribuição inibitória das bactérias ácido láticas durante a fermentação lática. Os autores alertam sobre a necessidade de uma grande superioridade numérica de BAL sobre qualquer patógeno presente no alimento fermentado. Os níveis de $S$. thermophilus e $L$. delbrueckii subsp. bulgaricus na presente pesquisa (cerca de $10^{8}-10^{9} \mathrm{UFC} / \mathrm{mL}$ cada) são numericamente bem maiores que a população de $E$. coli 0157:H7 $\left(10^{4} \mathrm{UFC} / \mathrm{mL}\right)$, e podem ser uma explicação para a diminuição da viabilidade do patógeno. O efeito inibitório de BAL é uma das razões para 0 estabelecimento de uma concentração mínima de bactérias ácido láticas em iogurte em muitos países do mundo. No Codex Alimentarius e o Padrão de Identidade e Qualidade para Leites Fermentados no Brasil há exigência de uma população mínima de $10^{7} \mathrm{UFC} / \mathrm{mL}$ para bactérias ácido láticas totais $(4,7)$.

O aumento do consumo de iogurte desnatado no mercado está relacionado à procura de alimentos saudáveis pela população, porém não há muitos conhecimentos acerca de sua especificidade. Na presente pesquisa foram seguidos os procedimentos das manufaturas locais de iogurte a fim de que os resultados possam ser utilizados com mais precisão em uma caracterização de risco. A grande variedade de condições e manipulação dos fabricantes, entretanto, dificulta estabelecer qual o nível de uma contaminação natural do patógeno. Nesse estudo foi usado um nível de inóculo de $E$. coli 0157:H7 relativamente baixo $\left(10^{4} \mathrm{UFC} / \mathrm{mL}\right)$ em uma contaminação pósfermentação. Esse estágio do processamento é uma fonte potencial de contaminação em função do alto manuseio usado em pequenos laticínios durante a produção e envase. É importante lembrar que doses infectantes menores que aquelas utilizadas nesse estudo podem causar doenças alimentares $(15,20)$ e devem ser consideradas em outros experimentos.

Concluindo, embora as contagens do patógeno tenham caído continuamente, a sobrevivência de E. coli 0157:H7 foi detectada até o quarto 
BASTOS, P.A.M.B. et al. Sobrevivência de Escherichia coli O157:H7 em iogurtes contaminados pós-fermentação. PUBVET, Londrina, V. 7, N. 16, Ed. 239, Art. 1576, Agosto, 2013.

dia de estocagem, e isso pode ser um problema em pequenos laticínios locais, pois iogurtes produzidos recentemente são mais rapidamente disponíveis no mercado da região. O conteúdo de gordura do iogurte integral não foi suficiente a ponto de causar maior proteção sobre E. coli 0157:H7 quando comparado com iogurte desnatado e esse resultado permite o uso de modelos preditivos baseados no conhecimento corrente sobre ambos os tipos de iogurte.

\section{Referência Bibliográfica}

1. Adams, M.; Mitchell, R. (2002). Fermentation and pathogen control: a risk assessment approach. Int. J. Food Microbiol. 79, 75-83.

2. Kornacki, J.L.; Johnson, J.L. (2001). Enterobacteriaceae, coliforms, and Escherichia coli as quality and safety indicators. In: Downes, F.P.; Ito, K. (eds). Compedium of methods for the microbiological examination of foods. $\left(4^{\text {th }}\right.$ ed.). American Public Health Association, Washington. D.C., USA. p. 69-82.

3. Birollo, G.A.; Reinheimer, J.A.; Vinderola, C.G. (2000). Viability of lactic acid microflora in different types of yoghurt. Food Res. Int. 33, 799-805.

4. Brasil. (2000). Resolução no 05 de 13 de novembro de 2000. Oficializa os "Padrões de Qualidade e Identidade (PIQ) de Leites Fermentados". Diário Oficial da República Federativa do Brasil, DF, 27 nov. 2000, Seção 1, p. 9-12.

5. Chang, J-H.; Chou, C-C.; Li, C-F. (2000). Growth and survival of Escherichia coli O157:H7 during the fermentation and storage of diluted cultured milk drink. Food Microbiol. 17, 579-587.

6. Chung, H.J.; Bang, W.; Drake, M.A. (2006). Stress response of Escherichia coli. CRFSFS. 5, 52-64.

7. Codex Alimentarius Comission. 2003. Codex Standard for fermented milk. Codex Stan 243-2003. Available at:

<http://www.codexalimentarius.net/download/standards/400/CXS_243e.pdf > Acessed 16 Dec 2007.

8. Coia, J.E. (1998). Clinical, microbiological and epidemiological aspects of Escherichia coli 0157: H7 infection. FEMS Immunol. Med. Microbiol. 20, 1-9.

9. Dave, R.I.; Shah, N.P. (1998). Ingredient supplementation effects on viability of probiotic bacteria on yogurt. J. Dairy Sci. 81, 2804-2816.

10. Dlamini, B.C.; Buys, E.M. (2009). Adaptation of Escherichia coli O157:H7 to acid in traditional and commercial goat milk amasi. Food Microbiol. 26, 58-64.

11. Evrendilek, G. A. (2007). Survival of Escherichia coli O157:H7 in yogurt drink, plain yogurt and salted (tuzlu) yogurt: Effects of storage time, temperature, background flora and product characteristics. Int. J. Dairy Technol. 60 (2), 118-122. 
12. Faith, N.G.; Parniere, N.; Larson, T.; Lorang, T.D.; Luchansky, J.B. (1997). Viability of Escherichia coli $0157: \mathrm{H} 7$ in pepperoni during the manufacture of sticks and the subsequent storage of slices at 21,4 and $20^{\circ} \mathrm{C}$ under air and vacuum and $\mathrm{CO}_{2}$. Int. J. Food Microbiol. 37, 47-54.

13. Faith, N.G.; Wierzba, R.K.; Ihnot, A.M.; Rorering, A.M.; Lorang, T.D.; Kaspar, C.W.; Luchansky, J.B. (1998). Survival of Escherichia coli O157:H7 in full- and reduced-fat pepperoni after manufacture of sticks, storage of slices at $4^{\circ} \mathrm{C}$ or $21^{\circ} \mathrm{C}$ under air and vacuum, and baking of slices on frozen pizza at 135,191 and $246^{\circ} \mathrm{C}$. J. Food Prot. 61, 383-389.

14. Geornaras, I.; Yoon, Y.; Belk, K.E.; Smith, G.C.; Sofos, J.N. (2007). Antimicrobial activity of $\varepsilon$-Polylysine against Escherichia coli O157:H7, Salmonella typhimurium, and Listeria monocytogenes in various food extracts. Food Microbiol. Saf. 72 (8), 330-334.

15. Getty, K.J.K.; Thebus, R.K.; Marseden, J.L.; Fung, D.U.C.; Kastner, C.L. (2000). Escherichia coli 0157:H7 and fermented sausages: a review. J. Rapid Methods Autom. Microbiol. 8, 141-170.

16. Getty, K.J.K.; Synoground, A.; Roberts, M.N. (2007). Validation of heating conditions in production of direct acidified beef summer sausage for elimination of Escherichia coli 0157:H7. J. Food Saf. 27, 275-285.

17. Govaris, A.; Koidis, P.; Papatheodorou, K. (2002). Behaviour of Escherichia coli O157:H7 in sour milk, cows' milk yogurt and ewes' milk yogurt. J. Dairy Res. 69, 655-660.

18. Gulmez, M.; Guven, A. (2003). Survival of Escherichia coli O157:H7, Listeria monocytogenes $4 \mathrm{~b}$ and Yersinia enterocolitica $\mathrm{O} 3$ in different yogurt and kefir combinations as prefermentation contaminant. J. Appl. Microbiol. 95, 631-636.

19. Hsin-Yi, C.; Chou, C-C. (2001). Acid adaptation and temperature effect on the survival of E. coli $0157: \mathrm{H7}$ in acidic fruit juice and lactic fermented milk product. Int. J. Food Microbiol. 70, 189-195.

20. Jay, J. M. (2005). Microbiologia de Alimentos. Trad. Eduardo César Tondo et al. ( $6^{\text {th }}$ ed.). Artmed, Porto Alegre.

21. Kasimoğlu, A.; Akgün, S. (2004). Survival of Escherichia coli O157:H7 in the processing and post-processing stages of acidophilus yogurt. Int. J. Food Sci. Technol. 39, 563-568.

22. Lee, S.M.; Chen, J. (2005). The influence of an extracellular polysaccharide, comprised of colonic acid, on the fate of Escherichia coli $0157: \mathrm{H} 7$ during processing and storage of stirred yogurt. LWT. 38, 785-790.

23. Massa, S.; Altieri, C.; Quaranta, V.; De Pace, R. (1997). Survival of Escherichia coli O157: $\mathrm{H} 7$ in yoghurt during preparation and storage at $4^{\circ} \mathrm{C}$. Lett. Appl. Microbiol. 24, 347350.

24. Meng, J.; Feng, P.; Doyle, M. P. (2001). Pathogenic Escherichia coli. In: Downes, F.P.; Ito, K. (eds). Compedium of methods for the microbiological examination of foods. ( ${ }^{\text {th }}$ ed.). American Public Health Association, Washington. D.C., USA, p.331-341.

25. Morgan, D.; Newman, C.P.; Hutchinson, D.N.; Walker, A.M.; Rowe, B.; Majid, F. (1993). Verotoxin producing Escherichia coli $\mathrm{O} 157$ infections associated with the consumption of yoghurt. Epidemiol. Infect. 111, 181-187.

26. Mufandaedza, J.; Viljoen, B.C.; Feresu, S.B.; Gadaga, T.H. (2006). Antimicrobial properties of lactic acid bacteria and yeast-LAB cultures isolated from traditional fermented milk against pathogenic Escherichia coli and Salmonella enteritidis strains. Int. J. Food Microbiol. 108, 147-152. 
27. Ogawa, M.; Shimizu, K.; Nomoto, K.; Tanaka, R.; Hamabata, T.; Yamasaki, S.; Takeda, T.; Takeda, Y. (2001). Inhibition of in vitro growth of Shiga toxin-producing Escherichia coli $0157: \mathrm{H7}$ by probiotic Lactobacillus strains due to production of lactic acid. Int. J. Food Microbiol. 68, 135-140.

28. Robinson, R.K.; Tamime, A.Y. (1990). Microbiology of Fermented Milks. In: Robinson, R.K. (ed.). Dairy Microbiology: The Microbiology of Milk Products. ( $2^{\text {nd }}$ ed.). Elsevier Applied Science, London and New York, p.291-340.

29. Silva, N.; Amstalden, V.C.; Silveira, N.F.A. (2001). Manual de Métodos de Análise Microbiológica de Alimentos. 2 ed., Varela, São Paulo.

30. Simsek, B.; Sagdic, O.; Ozcelik, S. (2007). Survival of Escherichia coli O157: H7 during the storage of Ayran produced with different spices. J. Food Eng. 78, 676-680.

31. Tosun, H.; Seçkin, A.K.; Aktuğ Gönül, Ş. (2007). Acid adaptation effect on survival of Escherichia coli 0157:H7 in fermented milk products. Turk. J. Vet. Anim. Sci. 31 (1), 6166.

32. Tsegaye, M.; Ashenafi, M. (2005). Fate of Escherichia coli $\mathrm{O} 157: \mathrm{H} 7$ during the processing and storage of Ergo and Ayib, traditional Ethiopian dairy products. Int. J. Food Microbiol. $103,11-21$.

33. Van de Casteele, S.; Vanheruverzwijn, T.; Ruyssen, T.; Van Assche, P.; Swings, J.; Huys, G. (2006). Evaluation of culture media for selective enumeration of probiotic strains of lactobacilli and bifidobacteria in combination with yoghurt or cheese starters. Int. Dairy J. $16,1470-1476$.

34. Weir, E.; Hair, K. (2006). Escherichia coli - sporadic case or an outbreak? Can. Med. Assoc. J. 174 (12), 1711.

35. Williams, R.C.; Isaacs, S.; Decou, M.L.; Richardson, E.A.; Buffett, M.C.; Slinger, R.W.; Brodsky, M.H.; Ciebin, B.H.; Ellis, A.; Hockin J.; The E. coli O157:H7 Working Group. (2000). Illness outbreak associated with Escherichia coli O157:H7 in Genoa salami. Can. Med. Assoc. J. 162 (10), 1409-1413. 